\title{
Curcumin reduces a-synuclein induced cytotoxicity in Parkinson's disease cell model
}

\author{
Min S Wang 1,2, Shanta Boddapati ${ }^{1}$, Sharareh Emadi1 and Michael R Sierks ${ }^{* 1}$
}

\begin{abstract}
Background: Overexpression and abnormal accumulation of aggregated a-synuclein (aS) have been linked to Parkinson's disease (PD) and other synucleinopathies. as can misfold and adopt a variety of morphologies but recent studies implicate oligomeric forms as the most cytotoxic species. Both genetic mutations and chronic exposure to neurotoxins increase aS aggregation and intracellular reactive oxygen species (ROS), leading to mitochondrial dysfunction and oxidative damage in PD cell models.
\end{abstract}

Results: Here we show that curcumin can alleviate aS-induced toxicity, reduce ROS levels and protect cells against apoptosis. We also show that both intracellular overexpression of aS and extracellular addition of oligomeric aS increase ROS which induces apoptosis, suggesting that aggregated aS may induce similar toxic effects whether it is generated intra- or extracellulary.

Conclusions: Since curcumin is a natural food pigment that can cross the blood brain barrier and has widespread medicinal uses, it has potential therapeutic value for treating PD and other neurodegenerative disorders.

\section{Background}

Parkinson's disease (PD) affects $1 \%$ of the population over the age of 65 and is the second most common progressive neurodegenerative disorder after Alzheimer's disease (AD) [1,2]. The classical symptoms of PD include resting tremor, muscular rigidity and bradykinesia $[2,3]$ resulting from the progressive loss of dopaminergic neurons in the substantia nigra region of the brain [3,4]. Intracellular inclusions known as Lewy bodies (LB) and Lewy neurites (LN), composed primarily of insoluble aggregates of ubiquitin and $\alpha$-synuclein $(\alpha S)$, are neuropathological hallmarks of PD found in many regions of the brain and central nervous system (CNS) [4-6]. Point mutations and multiplication of the $\alpha \mathrm{S}$ gene are associated with rare early onset familial forms of the disease, further implicating the role of $\alpha \mathrm{S}$ in PD [7-10]. The increased degeneration of dopaminergic neurons in the substantia nigra of PD animal models correlates with increased levels of LBs and LNs in this region of the brain and strongly suggests

* Correspondence: sierks@asu.edu

1 Department of Chemical Engineering, Arizona State University, Tempe, AZ 85287-6006 USA

Full list of author information is available at the end of the article that overexpression of $\alpha \mathrm{S}$ selectively targets dopaminergic neurons [11-13]. While it is unclear why dopaminergic neurons are more susceptible to degeneration by $\alpha \mathrm{S}$, the oxidation of dopamine and exposure to neurotoxins such as rotenone $[14,15]$ and 1-methyl-4-phenyl-1,2,3,6tetrahydropyridine (MPTP) [16-19] generate excessive reactive oxygen species (ROS), promoting mitochondrial complex I dysfunction $[15,20,21]$ and depleting glutathione levels $[22,23]$ ultimately causing acute Parkinsonism in animal and cell models. In addition, overexpression of both wild type (WT) and mutant $\alpha \mathrm{S}$ results in formation of cytoplasmic inclusions and degeneration of dopaminergic neurons in mouse and Drosophila models [11$13,24]$.

$\alpha \mathrm{S}$ is a presynaptic protein expressed at synaptic terminals in the CNS $[25,26]$. While $\alpha \mathrm{S}$ is a natively unfolded protein, the monomeric form can misfold and aggregate into larger oligomeric and fibrillar forms which are linked to the pathogenesis of PD. Recent studies have implicated small soluble oligomeric and protofibrillar forms of $\alpha \mathrm{S}$ as the most neurotoxic species [27-30]. While previous studies provide good evidence for the intracellular toxicity of $\alpha \mathrm{S}$ in $\mathrm{PD}$, there is also evidence showing an extracel- 
lular component as well [27-29,31,32]. Monomeric and oligomeric forms of $\alpha \mathrm{S}$ have been detected in blood plasma and cerebrospinal fluid of PD patients [27,31-33], and exposure to extracellular pre-aggreated $\alpha \mathrm{S}$ induces cytotoxicity in primary mesencephalic neuron-glia and human neuroblastoma cell cultures $[28,29,34,35]$.

Since generation of ROS has been correlated with onset of PD, anti-oxidants may have therapeutic value. Curcumin, a polyphenolic compound commonly used as food additives in Asian cuisine, has anti-oxidant properties and suppresses inflammatory responses of brain microglial cells [36-38]. Curcumin was also shown to have protective effects in neurodegenerative disease by either reducing inflammation and oxidative damage in AD [36-39], or by inhibiting protein misfolding and aggregation in Creutzfeld-Jakob disease [40] and PD $[41,42]$.

Given these numerous beneficial properties, curcumin shows promise as a therapeutic agent for neurodegenerative diseases. We show that curcumin can provide protection against $\alpha \mathrm{S}$-induced cytotoxicity in SH-SY5Y neuroblastoma cells by decreasing cytotoxicity of aggregated $\alpha \mathrm{S}$, reducing intracellular ROS, inhibiting caspase-3 activation and ameliorating signs of apoptosis. We also show that either extracellular addition of oligomeric $\alpha \mathrm{S}$ and intracellular overexpression of $\alpha \mathrm{S}$ increases generation of intracellular ROS in SH-SY5Y cells and both have similar cytotoxic effects resulting in induced caspase-3 activity and apoptosis.

\section{Results}

\section{Curcumin protects SH-SY5Y cells against extracellular aS-} induced cytotoxicity

Extracellular incubation of SH-SY5Y cells with oligomeric but not monomeric or fibrillar $\alpha \mathrm{S}$ induced significant cytotoxicity (Fig. 1) in agreement with previous studies implicating oligomeric $\alpha \mathrm{S}$ as the toxic species [2730]. While co-incubation of curcumin does not alter the monomeric and pre-formed oligomeric $\alpha S$ morphologies, it does destabilize pre-formed $\alpha \mathrm{S}$ fibrils (Fig. 1A, Additional file 1), consistent with previous results [41]. PAGE and AFM size distribution data also confirm that curcumin does not alter the molecular weight or size of the oligomeric $\alpha S$ species (Fig. $1 \mathrm{~B}$ and $1 \mathrm{C}$ ). Toxicity assays show that addition of curcumin significantly reduces the $\alpha S$-induced toxicity induced by pre-formed oligomeric $\alpha S$ while co-incubation of curcumin with pre-formed $\alpha S$ fibrils shows a significant increase in toxicity (Fig. 1D). Co-incubation of curcumin with monomeric $\alpha S$ does not alter cytotoxicity (Fig. 1D) similar to incubation with curcumin and Tris buffer alone (Table 1). Toxicity studies of curcumin alone towards SH-SY5Y cells showed no toxic effects at concentrations below $5 \mu \mathrm{M}$ (data not shown). Since only oligomeric $\alpha \mathrm{S}$ aggregates induced toxicity in
SH-SY5Y cells, subsequent experiments were performed with oligomeric $\alpha \mathrm{S}$ to determine the protective effects of curcumin against $\alpha \mathrm{S}$.

\section{Extracellular addition of aS generates excessive ROS}

When oligomeric $\alpha \mathrm{S}$ was added extracellularly to $\mathrm{SH}$ SY5Y cells, the intracellular ROS level significantly increased from $100 \pm 3.8$ (control) to $165.4 \pm 11.8$ (Fig. $2 \mathrm{~A})$, indicating that extracellular $\alpha \mathrm{S}$ enhances ROS levels in SH-SY5Y cells. Treatment with curcumin substantially reduces this increase in intracellular ROS levels to $118.5 \pm$ 4.6 (Fig. 2A). Curcumin and Tris buffer alone did not affect ROS levels (Fig. 2A). The ability of curcumin to reduce ROS levels generated by oligomeric $\alpha \mathrm{S}$ is consistent with results obtained using anti-oxidants in $\mathrm{MPP}^{+}$ PD models $[17,20,43]$ providing further evidence that ROS plays a central role in the selective degeneration of dopaminergic neurons in PD.

\section{Curcumin inhibits caspase- 3 activity and apoptosis induced by extracellular aS}

In addition to increasing ROS levels, extracellular incubation of SH-SY5Y cells with oligomeric $\alpha \mathrm{S}$ also activates caspase-3 activity and triggers apoptosis. Caspase-3 activity in the oligomeric $\alpha \mathrm{S}$-treated sample increased by 2.4-fold compared to the control, while pre-incubation of curcumin with $\alpha \mathrm{S}$ reduced the increase in caspase- 3 activation by almost half (Fig. 2B). Addition of curcumin and Tris buffer alone had no significant effects on caspase-3 activity (Fig. 2B). Extracellular addition of oligomeric $\alpha S$ to SH-SY5Y cells also induced apoptosis in the cells as marked by the changes in morphologies of the cell nuclei. While the control SH-SY5Y cells had regular nuclei with uniformly dispersed chromatin and intact cell membrane (Fig. 3A), cells incubated with oligomeric $\alpha \mathrm{S}$ showed signs of apoptosis as indicated by condensed nuclei and intense fluorescence staining with Hoechst dye (Fig. 3B). Pre-incubation of curcumin with $\alpha S$ reduced nuclear damage induced by extracellular oligomeric $\alpha \mathrm{S}$ (Fig. 3C) while curcumin alone did not affect the nuclear morphology of the cells (Fig. 3D).

\section{Curcumin reduces ROS and cytotoxicity induced by intracellular overexpression of aS}

While curcumin provided substantial protection against extracellular $\alpha S$-induced toxicity, PD pathology includes intracellular aggregation and accumulation of $\alpha \mathrm{S}$. We evaluated whether extracellularly added curcumin can also protect against intracellularly induced $\alpha \mathrm{S}$ toxicity by overexpressing $\alpha \mathrm{S}$ in SH-SY5Y cells by transient transfection with a WTsynEGFP gene. The $\alpha \mathrm{S}$-transfected cells showed intracellular eGFP fluorescence, indicating $\alpha \mathrm{S}$ expression (Fig. 4A). The level of $\alpha \mathrm{S}$ overexpression was estimated to be around $10 \%$ from 3 independent experi- 

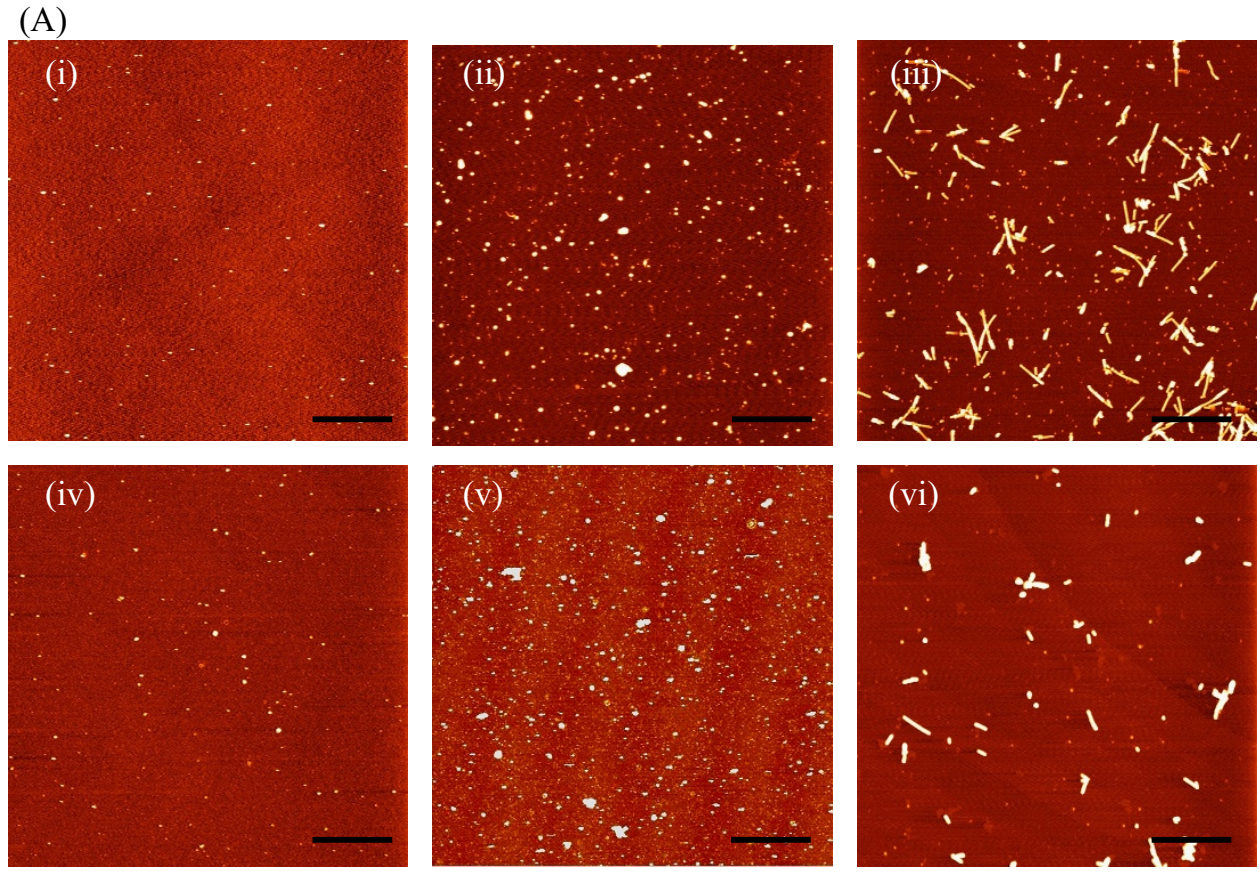

(B)
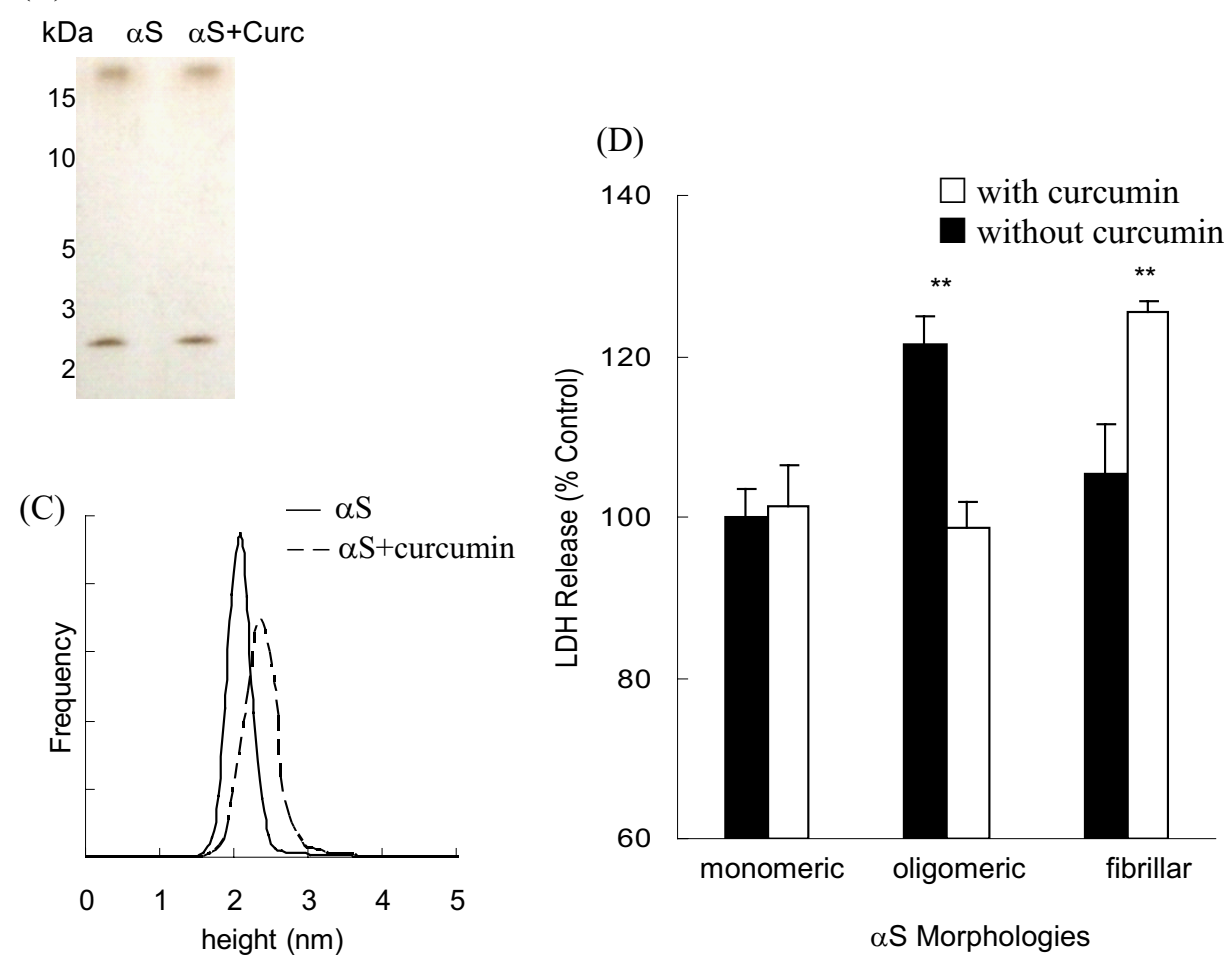

Figure 1 Oligomeric aS induces cytotoxicity in SH-SY5Y cells. Conformation and cytotoxicity of aS with and without curcumin addition observed by AFM imaging, PAGE and LDH assay. (A) AFM images of aS alone: (i) monomeric aS, (ii) pre-formed oligomeric aS and (iii) fibrillar aS; and aS coincubated with curcumin for 2-h: (iv) monomeric aS, (v) pre-formed oligomeric aS and (vi) and fibrillar aS. Scale bar $=1 \mu \mathrm{m}$. (B) Pre-formed oligomeric aS samples, with and without curcumin were separated on a 10\% Tris/Tricine native PAGE gel and analyzed using silver staining. (C) Height distribution of oligomeric aS samples. Particle heights of pre-formed oligomeric aS samples, with (--) and without curcumin (-) were analyzed using AFM and SPIP software. (D) LDH activity of SH-SY5Y cells incubated with different morphologies of aS with or without co-incubation with curcumin. LDH release was expressed as a percentage of the Tris control samples. Data was reported as mean $\pm \mathrm{SE}, n=4 .{ }^{* *} \mathrm{p}<0.01$ compared with the untreated control samples. 
Table 1: Curcumin neutralizes aS-induced cytotoxicity in SH-SY5Y cells

\begin{tabular}{ccccccc}
\hline Sample & $\begin{array}{c}\text { LDH (\% } \\
\text { control) }\end{array}$ & SE & p-value & $\begin{array}{c}\text { Viability (\% } \\
\text { control) }\end{array}$ & SE & p-value \\
\hline $\begin{array}{c}\text { Tris buffer } \\
\text { (control) }\end{array}$ & 100 & 2.4 & NA & 100 & 4.3 & NA \\
aS & 121.5 & 3.5 & $0.005^{\mathrm{a}}$ & 67.9 & 1.9 & $0.004^{\mathrm{a}}$ \\
aS + curcumin & 99.7 & 5.3 & $0.018^{\mathrm{b}}$ & 89.1 & 4.1 & $0.008^{\mathrm{b}}$ \\
Curcumin & 99.3 & 4.9 & 0.936 & 96.8 & 5.6 & 0.501 \\
\hline
\end{tabular}

Cytotoxicity was measured using LDH assay and cell viability was determined using resazurin reduction assay. SH-SY5Y cells were incubated with Tris buffer (control), aS, aS+curcumin and curcumin for $48 \mathrm{hr}$ before analysis. The LDH release and cell viability were expressed as a percentage of the untreated samples. Data was reported as mean $\pm \mathrm{SE}, n=4$. ${ }^{\mathrm{c}} \mathrm{compared}$ with the control; ${ }^{\mathrm{b}}$ compared with aS-treated samples.

ments, which was typical for this cell line [9]. The eGFP fluorescence intensity and the $\alpha \mathrm{S}$ levels were markedly reduced in the curcumin treated sample, suggesting a suppressive effect of curcumin on $\alpha \mathrm{S}$ expression (Fig. 4A). Intracellular ROS levels in the $\alpha \mathrm{S}$-transfected cells increased over 2-fold compared to untransfected cells, while treatment with curcumin reduced the increase in ROS level to just $40 \%$ over the control value (Fig. 4B). Similarly, intracellular $\alpha \mathrm{S}$ increased LDH release by $40 \%$

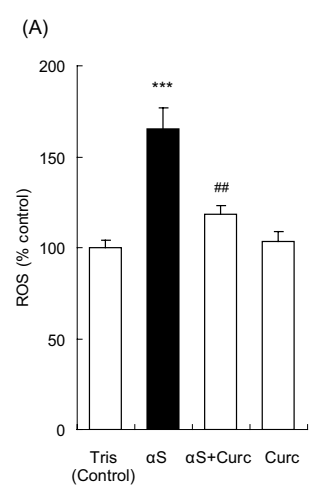

(B)

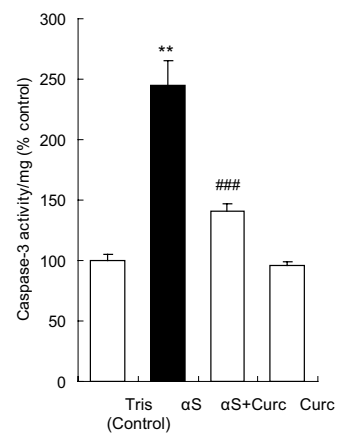

Figure 2 Curcumin reduces aS-induced intracellular ROS generation and inhibits caspase-3 activation in SH-SY5Y cells. SH-SY5Y cells were incubated with Tris buffer, oligomeric aS, aS+curcumin and curcumin and the intracellular ROS and caspase-3 activity were determined using cell based assays. (A) Intracellular ROS was determined by DCF fluorescence. DCFH-DA was then added to each well and the plate was incubated at $37^{\circ} \mathrm{C}$ for an additional $1 \mathrm{hr}$. The fluorescence intensity of DCF was measured at Ex $485 \mathrm{~nm}$ and Em $535 \mathrm{~nm}^{\prime}$ respectively. The increase in DCF fluorescence was expressed as a percentage of the control and is a direct measurement of intracellular ROS due to the oxidation of DCFH-DA to DCF by intracellular ROS. (B) Caspase-3 activity was determined by the absorbance of pNA substrate. After $24 \mathrm{~h}$ of treatment, the cells were detached, lysed and an equal protein loading was added to the $2 \times$ reaction buffer with DTT and DEVD-pNA substrate. After $1 \mathrm{hr}$ of incubation at $37^{\circ} \mathrm{C}$, the absorbance intensity was measured at $405 \mathrm{~nm}$ and the caspase-3 activity was reported percentage of the Tris buffer control. Data was analyzed using one way ANOVA followed by Bonferroni post-hoc test and reported as mean $\pm \mathrm{SE}, n=4$. ${ }^{* *} p<0.01,{ }^{* * *} p<0.001$, compared with the untreated samples; and $\# \# p<0.01, \# \# p<0.001$, compared with aS-treated samples compared to the control cells and addition of curcumin reduced the LDH increase to just 20\% (Fig. 4C). The overexpression of $\alpha \mathrm{S}$ significantly increased ROS and LDH levels and addition of curcumin alleviated these effects, even with the low expression levels studied. Curcumin therefore has similar potent protective effects against $\alpha \mathrm{S}$ cytotoxicity regardless of whether $\alpha \mathrm{S}$ toxicity is induced extra- or intracellularly.

\section{Discussion}

A key pathological feature of PD is the formation of cytoplasmic inclusions containing ubiquitin and $\alpha \mathrm{S}$ known as LBs and LNs in the dopaminergic neurons of the substantia nigra region of the brain [3,4]. The many factors that influence $\alpha \mathrm{S}$ aggregation and the subsequent downstream cytotoxic events that lead to neuronal cell death
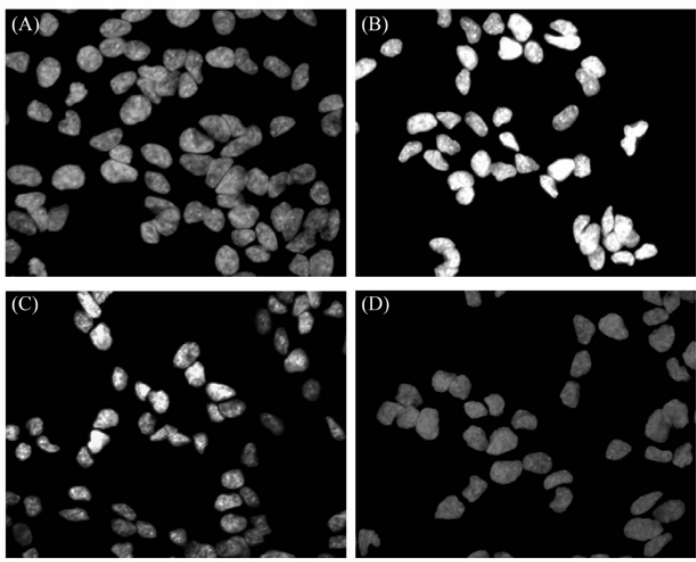

Figure 3 Curcumin ameliorates aS-induced morphological changes in SH-SY5Y cells evaluated by fluorescence microscopy. After $48 \mathrm{hr}$ incubation, cells were fixed with $4 \%$ paraformaldehyde, stained with Hoechst $33342(5 \mathrm{mg} / \mathrm{mL})$ and analyzed using a Nikon TE300 fluorescence microscope. Fluorescence micrographs (100X magnification) of the (A) control cells, (B) cells exposed to aS, (C) cells exposed to aS+curcumin and (D) curcumin. 
(A)

DIC
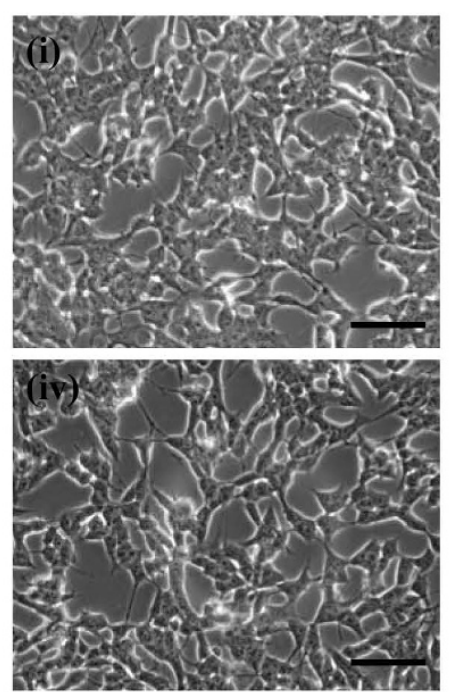

GFP
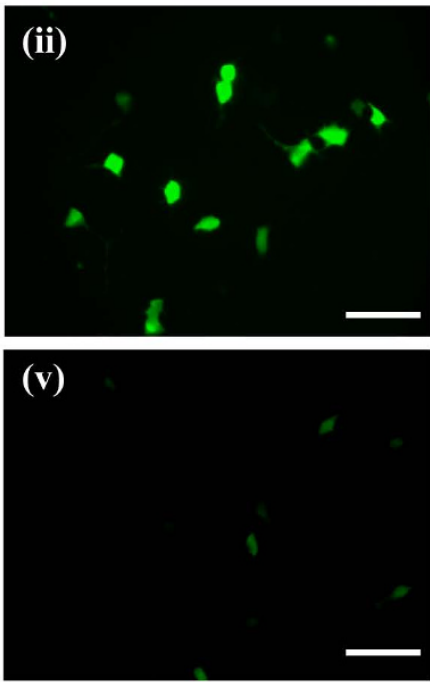

Overlay
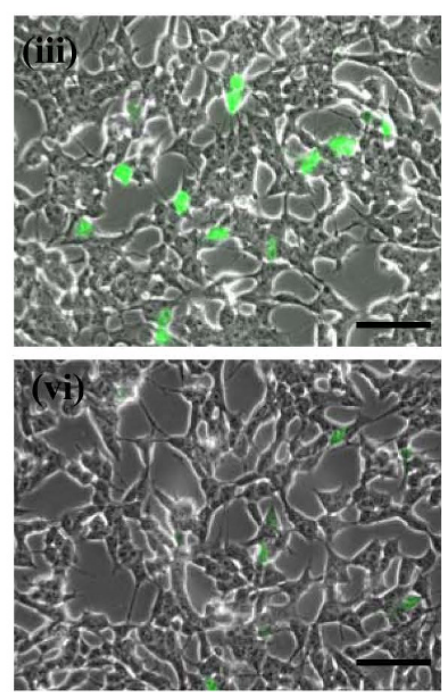

(B)

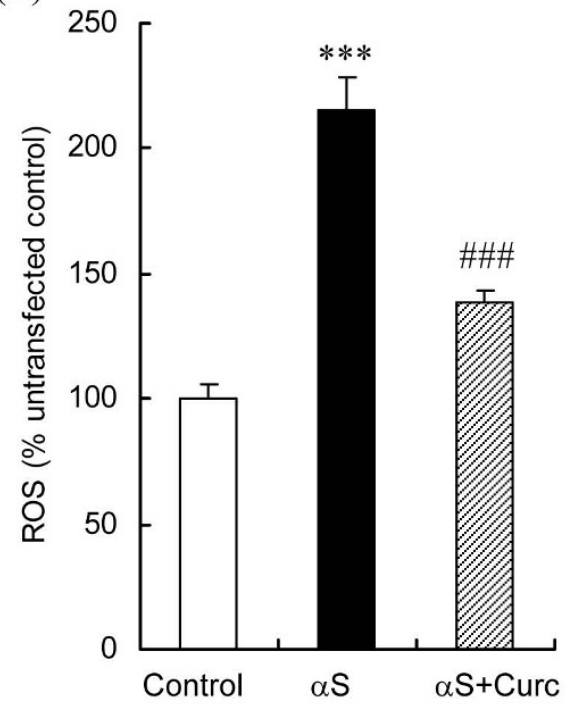

(C)

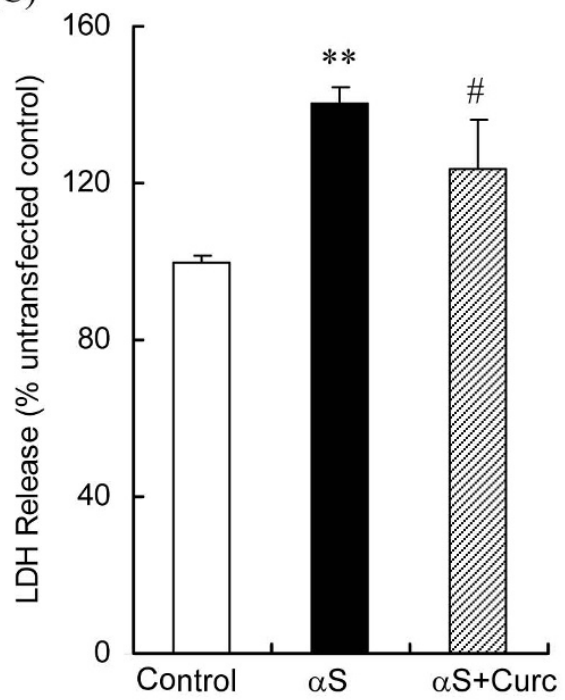

Figure 4 Curcumin reduces intracellular ROS and cytotoxicity of transiently transfected WTaS-EGFP SH-SY5Y cells. Localization of WTaSEGFP and protective effects of curcumin in transiently transfected SH-SY5Y cells. (A) Representative images of WTaS-EGFP transfected cells in the absence (i-iii) and presence of curcumin (iv-vi) were captured using a Nikon TE300 fluorescence microscope. Scale bar $=50 \mu \mathrm{m}$. (B) ROS levels and (C) cytotoxicity of the untransfected control, aS-transfected and aS-transfected+curcumin were measured. For LDH assay, cell culture media was collected after $48 \mathrm{hr}$ and the LDH release was expressed as a percentage of the untransfected samples. For ROS measurements, DCFH was added to each well and the DCF fluorescence was measured at $\mathrm{Ex}_{485 \mathrm{~nm}}$ and $\mathrm{Em}_{535 \mathrm{~nm}}$ after an additional incubation at $37^{\circ} \mathrm{C}$ for $30 \mathrm{~min}$. DCF fluorescence was expressed as a percentage of the untransfected control reported as mean $\pm \mathrm{SD}, n=3$. ${ }^{* *} p<0.01$; ${ }^{* *} \mathrm{p}<0.001$, compared with the untransfected control, $\# p<0.05$; \#\# $>0.001$ compared with aS-transfected sample analyzed using one way ANOVA followed by Bonferroni post-hoc test. 
are being actively studied. Several point mutations in the $\alpha S$ gene which correlate to rare familial early-onset PD and rapid progression of the disease [7-9] accelerate aggregation of $\alpha \mathrm{S}$ and favor formation of nonfibrillar oligomeric forms. Recent studies have suggested that soluble oligomeric and protofibrillar structures are the toxic species [27-30], and that these forms can permeabilize plasma membranes, alter intracellular function, induce oxidative stress and trigger apoptosis in cells [30,44,45]. Epidemiological studies have also suggested that exposure to environmental agents such as neurotoxins and pesticides [16,17] cause an increase in oxidative damage to the cells by suppressing mitochondrial complex I activity and reducing glutathione levels [22,23], thereby increasing the risk for PD.

Oxidative stress plays a major role in aging and is associated with several neurodegenerative diseases including PD [46], where an increase in ROS accompanies $\alpha S$ aggregation and degeneration of dopaminergic neurons $[15,47,48]$. Intracellular overexpression of $\alpha \mathrm{S}$ generates excess ROS and causes oxidative stress to the cells $[23,46]$, leading to disruption in redox homeostasis cell metabolism, free radical generation, lipid peroxidation, cholesterol and protein oxidation $[46,49]$. Excess ROS causes plasma membrane damage, mitochondrial dysfunction, defects in the glutathione peroxidase expression and reduction in glutathione levels, all of which render the brain more susceptible to oxidative stress $[46,49,50]$. In this study, we find that extracellular addition of oligomeric $\alpha \mathrm{S}$ and intracellular overexpression of $\alpha \mathrm{S}$ in SHSY5Y cells both increase ROS levels by almost 2 -fold. The $\alpha \mathrm{S}$-induced increase in ROS levels in our current study shows similar oxidative damage to the SH-SY5Y cell as previous $\mathrm{MPP}+\mathrm{PD}$ cell models, where $\mathrm{MPP}^{+}$selectively targets and degenerates dopaminergic neurons due to excess generation of ROS $[13,15,18]$. Prolonged exposure to $\mathrm{MPP}^{+}$and other neurotoxins has been shown to activate caspase-3 $[16,19,51]$, an important effector caspase in the final apoptotic cascade leading to cell death. If oxidative stress exacerbates the etiology of $\mathrm{PD}$, then agents that can simultaneously attenuate ROS damage and suppress caspase- 3 activation may hold promise for the treatment of PD and other neurodegenerative diseases.

Here we show that curcumin, a natural phenolic food additive, effectively inhibits activation of caspase-3 (Fig. 2B) and ameliorates signs of apoptosis (Fig. 3) induced by extracellular addition of oligomeric $\alpha \mathrm{S}$ to SH-SY5Y cells. We also demonstrated that curcumin reduces intracellular overexpression of $\alpha \mathrm{S}$ and reduces ROS generation $[15,46,48]$.

\section{Conclusions}

Overexpression and abnormal accumulation of oligomeric $\alpha \mathrm{S}$ is key in the pathogenesis of $\mathrm{PD}[14,48,52]$, and numerous studies suggest that there is both an intra- and extracellular component to $\alpha S$ toxicity in PD $[12,24,31,32,53]$. We recently demonstrated that an antioligomeric $\alpha \mathrm{S}$ antibody fragment binds oligomeric $\alpha \mathrm{S}$ on the surface of SH-SY5Y cells, verifying the presence of intracellularly produced oligomeric $\alpha \mathrm{S}$ on external cell membrane surfaces [29]. Here we show that extracellular addition of oligomeric $\alpha \mathrm{S}$ induces similar cytotoxic effects as intracellular overexpression of $\alpha S$, and that these $\alpha \mathrm{S}$-induced cytotoxic effects are similar to those reported in MPTP Parkinsonian models. We also show that curcumin can significantly reduce the cytotoxicity induced by extracellular or intracellular $\alpha \mathrm{S}$ aggregates, suggesting it may have value for treating PD. Since extracellularly added curcumin provides protection even against intracellularly induced $\alpha \mathrm{S}$ toxicity, our results suggest that there is a significant extracellular or cell surface component of $\alpha \mathrm{S}$-induced toxicity in PD models, which is consistent with a recently published report of interneuronal transmission of extracellular $\alpha \mathrm{S}$ pathology in neuronal cells [53]. However, additional studies are needed to further elucidate the mechanism of $\alpha \mathrm{S}$ induced cytotoxicity and its subsequent pathogenesis and progression to induced-apoptosis in PD.

\section{Methods}

\section{a-synuclein aggregation}

$\alpha \mathrm{S}$ was prepared and purified in our lab as previously described $[28,54]$. Purified $\alpha \mathrm{S}$ was lyophilized and stored at $-80^{\circ} \mathrm{C}$ until further use. Stocks of the lyophillized $\alpha \mathrm{S}$ were first dissolved in DI water and subsequent dilutions were made in Tris buffer ( $25 \mathrm{mM}$ Tris, $150 \mathrm{mM} \mathrm{NaCl}, \mathrm{pH}$ 7.4). The various forms of $\alpha \mathrm{S}$ samples $(70 \mu \mathrm{M})$ were prepared by dissolving the $\alpha \mathrm{S}$ stock in Tris buffer. Monomeric $\alpha \mathrm{S}$ samples were utilized immediately after dilution with Tris buffer, oligomeric $\alpha \mathrm{S}$ were generated by incubating the samples at $37^{\circ} \mathrm{C}$ for 5-7 days (without shaking) while predominantly fibrillar morphologies of $\alpha \mathrm{S}$ were generated by incubation at $37^{\circ} \mathrm{C}$ for up to 30 days (without shaking). $\alpha \mathrm{S}$ morphologies were verified by AFM before use. All other chemicals were purchased from Sigma-Aldrich (Sigma-Aldrich, MO) and used as is without further treatment unless otherwise specified.

\section{Co-incubation of curcumin with pre-formed aS samples}

Curcumin stocks $(1 \mathrm{mg} / \mathrm{mL})$ were prepared in dimethyl sulfoxane (DMSO) and stored at $-20^{\circ} \mathrm{C}$ in dark conditions until use. Curcumin was diluted to $140 \mu \mathrm{M}$ with Tris buffer in a 2:1 molar ratio of curcumin to pre-formed $\alpha \mathrm{S}$ sample.

\section{Atomic Force Microscopy}

A $10 \mathrm{uL}$ aliquot of each sample was applied to a piece of freshly cleaved mica, incubated at room temperature for 
10 minutes, rinsed with DI water and dried under a gentle stream of $\mathrm{N}_{2}$ gas. Topographic AFM images were acquired using OTESPA tips $\left(\mathrm{k}=40 \mathrm{~N} / \mathrm{m}, f_{\mathrm{o}}=300-\mathrm{kHz}\right)$ (Veeco, Santa Barbara, CA) at scan rates of $2 \mathrm{~Hz}$ with 512 $\times 512$ pixel resolution on a Nanoscope IIIa TM-AFM (Veeco, Santa Barbara, CA). AFM images were analyzed with the scanning probe imaging processor software (SPIP, Image Metrology) to generate height distribution plots, as previously described [55].

\section{PAGE and silver staining}

Oligomeric $\alpha \mathrm{S}$ samples, with and without curcumin were separated on a $10 \%$ Tris/Tricine native PAGE and developed using Pierce silver stain kit according to manufacturer's protocol. (Thermo Scientific, Rockford, IL).

\section{Cell culture and transient transfection of SH-SY5Y cells}

SH-SY5Y-human neuroblastoma cells were maintained and grown as described previously [28,29]. Transient transfection of SH-SY5Y cells was performed using TransFast $^{\mathrm{TM}}$ transfection reagent according to the manufacturer's protocol (Promega, Madison, WI) with slight modification. SH-SY5Y cells were grown for 4 days (50$65 \%$ confluency) in a 6 -well plate in vitro before transfection. A transfection mixture consisting of a $1 \mu \mathrm{g}$ aliquot of wildtype $\alpha$-synuclein/eGFP (WTsynEGFP) fusion protein plasmid DNA (Clontech, Palo Alto, CA) and TransFast ${ }^{\mathrm{TM}}$ reagent $(1: 2 \mathrm{v} / \mathrm{v})$ in serum free media was pre-incubated in the dark for $15 \mathrm{~min}$ at room temperature before addition to the cells. Cell culture media was removed and the transfection mixture $(500 \mu \mathrm{L})$ was added to each well and incubated for $1 \mathrm{hr}$ at $37^{\circ} \mathrm{C}$, followed by addition of complete media with serum $(500 \mu \mathrm{L})$. The culture plates were incubated and grown in a $5 \% \mathrm{CO}_{2}$ atmosphere at $37^{\circ} \mathrm{C}$ for $48 \mathrm{hrs}$. A $10 \mu \mathrm{L}$ aliquot of curcumin ( $4 \mu \mathrm{M}$ final concentration) was added $48 \mathrm{hr}$ post-transfection and the cells were incubated for another $24 \mathrm{hr}$ before analysis. Previous studies have shown that the $\alpha$-synuclein fusion protein aggregates similarly to $\alpha$-synuclein alone, and that eGFP expression does not induce toxicity [56].

\section{Cytotoxicity by lactate dehydrogenase assay}

Cytotoxicity of samples towards SH-SY5Y cells was measured using a lactate dehydrogenase (LDH) assay as described [57]. Cells were seeded $\left(2 \times 10^{4}\right.$ cells $\left./ \mathrm{mL}\right)$ in a 96-well plate $24 \mathrm{hr}$ prior to the following treatment conditions: (a) pre-formed oligomeric $\alpha \mathrm{S}(2 \mu \mathrm{M})$, (b) co-incubated samples of $\alpha \mathrm{S}(2 \mu \mathrm{M})$ with curcumin $(4 \mu \mathrm{M})$, (c) curcumin $(4 \mu \mathrm{M})$ and (d) Tris buffer control. After incubating cells with each treatment for $48 \mathrm{hr}$, cytotoxicity of each sample was determined by measuring the reduction of iodonitrotetrazolium salt by LDH enzyme using a Wallac 1420 plate reader (Perkin Elmer, USA) at $490 \mathrm{~nm}$ and
$650 \mathrm{~nm}$. The values were expressed as a percentage of the Tris buffer control. Experiments were repeated a minimum of three times.

\section{Cell viability by resazurin reduction assay}

Cell viability was determined using a resazurin reduction assay [58]. Viable cells convert resazurin (blue) to resorufin (pink), and the degree of cell death can be measured directly by either absorbance or fluorescence spectrometry. Resaruzin stocks $(10 \mathrm{mM})$ were made in DMSO and kept at $-20^{\circ} \mathrm{C}$ until use when they were diluted to a 100 $\mu \mathrm{M}$ working solution with Tris buffer. Cells were seeded $\left(5 \times 10^{4}\right.$ cells $\left./ \mathrm{mL}\right)$ in a 48 -well plate $24 \mathrm{hr}$ prior to exposure to the treatment conditions described above. Following treatment for $48 \mathrm{hr}$, cell culture media was removed and the cells were resuspended with $200 \mu \mathrm{L}$ Tris buffer. An aliquot $(10 \mu \mathrm{L})$ of resaruzin $(20 \mu \mathrm{M}$ final concentration) was added to each well and incubated at $37^{\circ} \mathrm{C}$ for an additional $3 \mathrm{hr}$. Absorbance of resorufin was measured at $560 \mathrm{~nm}$ and $600 \mathrm{~nm}$. Cell viability of each sample was calculated by subtracting the background $\mathrm{OD}_{600 \mathrm{~nm}}$ from $\mathrm{OD}_{560 \mathrm{~nm}}$ and reported as a percentage of the Tris buffer control.

\section{Measurement of intracellular ROS formation}

The formation of intracellular ROS was measured using a fluorescent probe, 2,7-dichlorofluorescein diacetate (DCFH-DA) as described [59]. The cells were seeded $(2 \times$ $10^{4}$ cells $/ \mathrm{mL}$ ) in a 96-well plate and were incubated for 48 hrs prior to ROS measurement with the conditions described above. After treatment, the cells were washed twice and resuspended in $100 \mu \mathrm{L}$ Tris buffer. DCFH-DA (10 $\mu \mathrm{M}$ final concentration) was added to each well and the cells were incubated for $1 \mathrm{hr}$ at $37^{\circ} \mathrm{C}$ in dark conditions. The fluorescence intensity of dichlorofluorescein (DCF, the oxidized species of DCFH-DA) was measured using a fluorescence spectrophotometer with excitation wavelength of $485 \mathrm{~nm}$ and emission wavelength of 535 $\mathrm{nm}$.

\section{Determination of caspase-3 activity}

Caspase-3 activity was determined using the Caspase-3/ CPP32 colorimetric assay kit following the manufacturer's protocol (BioVision, Inc., CA). Since caspase-3 is a pre-apoptotic marker, measurements of caspase-3 activity were taken after $24 \mathrm{hr}$ incubation with the various treatments to ensure proper detection. Briefly, cells $\left(10^{6}\right.$ cells $/ \mathrm{mL}$ ) were exposed to different treatments as described above for $24 \mathrm{hr}$, detached and lysed on ice for $10 \mathrm{~min}$. The supernatant was removed and the total protein concentration of each sample was determined using a bicinchoninic acid assay (BCA, Pierce, Rockford, IL). Cell lysate was then diluted to $150 \mu \mathrm{g}$ with lysis buffer for 
each assay. An equal loading amount of lysate $(50 \mu \mathrm{L})$ was mixed with $50 \mu \mathrm{L}$ of $2 \times$ reaction buffer with $10 \mathrm{mM}$ dithiothreitol (DTT) and $5 \mu \mathrm{L}$ DEVD-pNA substrate (200 $\mu \mathrm{M})$ and incubated at $37^{\circ} \mathrm{C}$ for $1 \mathrm{hr}$. The absorbance of released $p$-nitroanilide ( $p \mathrm{NA}$ ) was measured at $405 \mathrm{~nm}$ using a plate reader. The increase in caspase- 3 activity was determined by comparing the absorbance of the treated sample with the absorbance of the Tris buffer control sample.

\section{Fluorescence microscopy and nuclear staining}

WTsynEGFP-transfected cells were evaluated $48 \mathrm{hr}$ posttransfection using a Nikon TE300 fluorescence microscope at an excitation wavelength of $488 \mathrm{~nm}$ with a $40 \times$ magnification objective. For nuclear staining, untransfected SH-SY5Y cells were seeded on glass coverslips and allowed to attach for $24 \mathrm{hr}$. The cells were fixed with $4 \%$ paraformaldehyde for $25 \mathrm{~min}$, washed twice in cold Tris buffer, and stained with Hoechst $33342(10 \mu \mathrm{g} / \mathrm{mL})$ for 15 min. Nuclear morphology was observed using a $100 \times$ magnification objective. Images were captured and processed by MetaMorph software (Molecular Devices, USA). Cells stained by Hoechst 33342 with diffused nuclei were scored as viable, while cells with reduced nuclei, condensed chromatin, and increased fluorescence were considered apoptotic.

\section{Statistical Analysis}

Data was presented as mean \pm SE from at least three independent experiments. Statistical analysis was evaluated using either Student's t-test or using a one-way ANOVA followed by Bonferoni post-hoc test for all pairwise comparison. A p-value of $<0.05$ was considered as significant.

\section{Additional material}

Additional file 1 Curcumin alters aS aggregation kinetics. Aggregation kinetics were monitored using Thioflavin T assay. (A) monomeric aS and monomeric aS + curcumin, (B) pre-formed oligomeric aS and pre-formed oligomeric aS + curcumin, (C) pre-formed fibrillar aS and pre-formed fibrillar aS + curcumin. Samples were taken at the indicated time and mixed with Thioflavin T. The observed Thioflavin T fluorescence ( $E x=450 \mathrm{~nm}$, Em $=482 \mathrm{~nm}$ ) was normalized to each untreated aS sample at its maximum value. Data are presented as mean \pm SE from 4 sets of experiments.

\section{Authors' contributions}

MSW participated in the experimental design of the study, prepared preaggregated aS samples, conducted in vitro cell-based assays, performed fluorescence microscopy and statistical analysis and drafted the manuscript. SB maintained the untransfected SH-SY5Y cells, plated and added samples for all the in vitro assays and edited the manuscript. SE conducted transient transfection of SH-SY5Y cells and edited the manuscript. MRS supervised the design of study, provided technical assistance in data interpretation, and played a major part in revision of the manuscript. All authors read and approved the final manuscript.

\section{Acknowledgements}

This research was supported in part by grants from the Michael J. Fox Foundation, the Arizona Alzheimer's Research Consortium, American Health Assistance Foundation and the ASU Graduate and Professional Student Association Research Grant. The authors would like to thank Dr. Page Baluch and the WM Keck Imaging facility at ASU for the assistance with fluorescence microscopy and Mr. Philip Schulz for protein purification.

\section{Author Details}

1Department of Chemical Engineering, Arizona State University, Tempe, AZ 85287-6006 USA and 2Department of Chemistry, University of Colorado Denver, Denver, CO 80217-3364 USA

Received: 28 July 2009 Accepted: 30 April 2010

Published: 30 April 2010

\section{References}

1. Hoehn MM: Parkinsonism: Onset progression and mortality Commentary. Neurology 1998, 50(2):318-318.

2. Recchia A, Debetto P, Negro A, Guidolin D, Skaper SD, Giusti P: alphasynuclein and Parkinson's Disease. Faseb J 2004, 18(6):617-626.

3. Lotharius J, Brundin P: Pathogenesis of Parkinson's disease: dopamine, vesicles and alpha-synuclein. Nat Rev Neurosci 2002, 3(12):932-942.

4. Gomez-Tortosa E, Newell K, Irizarry MC, Albert M, Growdon JH, Hyman BT: Clinical and quantitative pathologic correlates of dementia with Lewy bodies. Neurology 1999, 53(6):1284-1291.

5. Spillantini M, Crowther R, Jakes R, Cairns N, Lantos P, Goedert M: Filamentous alpha-synuclein inclusions link multiple system atrophy with Parkinson's disease and dementia with Lewy bodies. Neurosci Lett 1998, 251(3):205-208.

6. Spillantini M, Crowther R, Jakes R, Hasegawa M, Goedert M: alphasynuclein in filamentous inclusions of Lewy bodies from Parkinson's disease and dementia with Lewy bodies. P Natl Acad Sci USA 1998 95(11):6469-6473.

7. Conway KA, Lee SJ, Rochet JC, Ding TT, Williamson RE, Lansbury PT: Acceleration of oligomerization, not fibrillization, is a shared property of both alpha-synuclein mutations linked to early-onset Parkinson's disease: Implications for pathogenesis and therapy. P Nat/ Acad Sci USA 2000, 97(2):571-576

8. Li J, Uversky VN, Fink AL: Effect of familial Parkinson's disease point mutations $\mathrm{A} 30 \mathrm{P}$ and $\mathrm{A} 53 \mathrm{~T}$ on the structural properties, aggregation, and fibrillation of human alpha-synuclein. Biochemistry 2001, 40(38):11604-11613.

9. Pandey N, Schmidt R, Galvin J: The alpha-synuclein mutation E46K promotes aggregation in cultured cells. EXP NEUROL 2006, 197(2):515-520

10. Singleton AB, Farrer $M$, Johnson J, Singleton A, Hague S, Kachergus J, Hulihan M, Peuralinna T, Dutra A, Nussbaum R, et al.: alpha-Synuclein locus triplication causes Parkinson's disease. Science 2003, 302(5646):841.

11. Auluck PK, Chan HYE, Trojanowski JQ, Lee VMY, Bonini NM: Chaperone suppression of alpha-synuclein toxicity in a Drosophila model for Parkinson's disease. Science 2002, 295(5556):865-868.

12. Feany MB, Bender WW: A Drosophila model of Parkinson's disease. Nature 2000, 404(6776):394-398.

13. Masliah E, Rockenstein E, Veinbergs I, Mallory M, Hashimoto M, Takeda A, Sagara Y, Sisk A, Mucke L: Dopaminergic loss and inclusion body formation in alpha-synuclein mice: Implications for neurodegenerative disorders. Science 2000, 287(5456):1265-1269.

14. Ahmadi FA, Grammatopoulos TN, Poczobutt AM, Jones SM, Snell LD, Das M, Zawada WM: Dopamine selectively sensitizes dopaminergic neurons to rotenone-induced apoptosis. Neurochem Res 2008, 33(5):886-901.

15. Sherer TB, Betarbet R, Testa CM, Seo BB, Richardson JR, Kim JH, Miller GW, Yagi T, Matsuno-Yagi A, Greenamyre JT: Mechanism of toxicity in rotenone models of Parkinson's disease. J Neurosci 2003, 23(34):10756-10764. 
16. Kalivendi SV, Cunningham S, Kotamraju S, Joseph J, Hillard CJ, Kalyanaraman B: alpha-synuclein up-regulation and aggregation during MPP+-induced apoptosis in neuroblastoma cells - Intermediacy of transferrin receptor iron and hydrogen peroxide. J Biol Chem 2004, 279(15):15240-15247.

17. Pettifer KM, Jiang SC, Bau C, Ballerini P, D'Alimonte I, Werstiuk ES, Rathbone MP: MPP+-induced cytotoxicity in neuroblastoma cells: Antagonism and reversal by guanosine. Purinerg Signal 2007, 3(4):399-409.

18. Przedborski S, Vila M: MPTP: a review of its mechanisms of neurotoxicity. Clin Neurosci Res 2001, 1(6):407-418.

19. Turmel H, Hartmann A, Parain K, Douhou A, Srinivasan A, Agid Y, Hirsch EC: Caspase-3 activation in 1-methyl-4-phenyl-1,2,3,6-tetrahydropyridine (MPTP)-treated mice. MOVEMENT DISORD 2001, 16(2):185-189.

20. Chen J, Tang XQ, Zhi JL, Cui Y, Yu HM, Tang EH, Sun SN, Feng JQ, Chen PX: Curcumin protects $\mathrm{PC} 12$ cells against 1-methyl-4-phenylpyridinium ion-induced apoptosis by $\mathrm{BCl}-2$-mitochondria-ROS-iNOS pathway. Apoptosis 2006, 11(6):943-953.

21. Srinivas BMM, Mythri R, Jagatha B, Vali S: Neuroprotective effect of curcumin against inhibition of mitochondrial complex I in vitro and in vivo: Implications for Parkinson's disease explained via in silico studies. J Neurochem 2008, 106:25-25.

22. Jagatha B, Mythri RB, Vali S, Bharath MMS: Curcumin treatment alleviates the effects of glutathione depletion in vitro and in vivo: Therapeutic implications for Parkinson's disease explained via in silico studies. Free Radical Bio Med 2008, 44(5):907-917.

23. Junn E, Mouradian MM: Human alpha-synuclein over-expression increases intracellular reactive oxygen species levels and susceptibility to dopamine. Neurosci Lett 2002, 320(3):146-150.

24. Lee VMY, Trojanowski JQ: Mechanisms of Parkinson's disease linked to pathological alpha-synuclein: New targets for drug discovery. Neuron 2006, 52(1):33-38

25. Iwai A: Properties of NACP/alpha-synuclein and its role in Alzheimer's disease. BBA-MOL BASIS DIS 2000, 1502(1):95-109.

26. Uversky VN, Li J, Souillac P, Millett IS, Doniach S, Jakes R, Goedert M, Fink $\mathrm{AL}$ : Biophysical properties of the synucleins and their propensities to fibrillate: inhibition of alpha-synuclein assembly by beta- and gammasynucleins. J Biol Chem 2002, 277(14):11970-11978.

27. El-Agnaf OM, Salem SA, Paleologou KE, Curran MD, Gibson MJ, Court JA, Schlossmacher MG, Allsop D: Detection of oligomeric forms of alphasynuclein protein in human plasma as a potential biomarker for Parkinson's disease. Faseb J 2006, 20(3):419-425.

28. Emadi S, Barkhordarian H, Wang MS, Schulz P, Sierks MR: Isolation of a human single chain antibody fragment against oligomeric alphasynuclein that inhibits aggregation and prevents alpha-synucleininduced toxicity. J Mol Biol 2007, 368(4):1132-1144.

29. Emadi S, Kasturirangan S, Wang MS, Schulz P, Sierks MR: Detecting morphologically distinct oligomeric forms of alpha-synuclein. J Biol Chem 2009, 284(17):11048-11058.

30. Lashuel HA, Hartley D, Petre BM, Walz T, Lansbury PT Jr: Neurodegenerative disease: amyloid pores from pathogenic mutations. Nature 2002, 418(6895):291.

31. Borghi R, Marchese R, Negro A, Marinelli L, Forloni G, Zaccheo D, Abbruzzese G, Tabaton M: Full length alpha-synuclein is present in cerebrospinal fluid from Parkinson's disease and normal subjects. Neurosci Lett 2000, 287(1):65-67.

32. El-Agnaf OM, Salem SA, Paleologou KE, Cooper LJ, Fullwood NJ, Gibson MJ, Curran MD, Court JA, Mann DM, Ikeda S, et al:: Alpha-synuclein implicated in Parkinson's disease is present in extracellular biological fluids, including human plasma. Faseb J 2003, 17(13):1945-1947.

33. Jakowec MW, Petzinger GM, Sastry S, Donaldson DM, McCormack A, Langston JW: The native form of alpha-synuclein is not found in the cerebrospinal fluid of patients with Parkinson's disease or normal controls. Neurosci Lett 1998, 253(1):13-16.

34. Walsh DM, Selkoe DJ: Oligomers on the brain: the emerging role of soluble protein aggregates in neurodegeneration. Protein Pept Lett 2004, 11(3):213-228

35. Zhang W, Wang T, Pei Z, Miller DS, Wu X, Block ML, Wilson B, Zhang W, Zhou Y, Hong JS, et al:: Aggregated alpha-synuclein activates microglia: a process leading to disease progression in Parkinson's disease. Faseb $J$ $2005,19(6): 533-542$
36. Begum AN, Jones MR, Lim GP, Morihara T, Kim P, Heath DD, Rock CL, Pruitt $M A$, Yang FS, Hudspeth B, et al:: Curcumin structure-function, bioavailability, and efficacy in models of neuroinflammation and Alzheimer's disease. J Pharmacol Exp Ther 2008, 326(1):196-208.

37. Cole GM, Morihara T, Lim GP, Yang FS, Begum A, Frautschy SA: NSAID and antioxidant prevention of Alzheimer's disease lessons from in vitro and animal models. Ann N Y Acad Sci 2004, 1035:68-84.

38. Frautschy SA, Hu W, Kim P, Miller SA, Chu T, Harris-White ME, Cole GM: Phenolic anti-inflammatory antioxidant reversal of $A$ beta-induced cognitive deficits and neuropathology. Neurobiol Aging 2001, 22(6):993-1005

39. Lim GP, Chu T, Yang FS, Beech W, Frautschy SA, Cole GM: The curry spice curcumin reduces oxidative damage and amyloid pathology in an Alzheimer transgenic mouse. J Neurosci 2001, 21(21):8370-8377.

40. Hafner-Bratkovic I, Gaspersic J, Smid LM, Bresjanac M, Jerala R: Curcumin binds to the alpha-helical intermediate and to the amyloid form of prion protein - a new mechanism for the inhibition of PrPSC accumulation. J Neurochem 2008, 104(6):1553-1564.

41. Ono K, Yamada M: Antioxidant compounds have potent antifibrillogenic and fibril-destabilizing effects for alpha-synuclein fibrils in vitro. J Neurochem 2006, 97(1):105-115.

42. Pandey N, Strider J, Nolan WC, Yan SX, Galvin JE: Curcumin inhibits aggregation of alpha-synuclein. Acta Neuropathol 2008, 115(4):479-489.

43. Wang XH, Xu JX: Salvianic acid A protects human neuroblastoma SHSY5Y cells against MPP+-induced cytotoxicity. Neurosci Res 2005, 51(2):129-138.

44. Caughey B, Lansbury PT: Protofibrils, pores, fibrils, and neurodegeneration: separating the responsible protein aggregates from the innocent bystanders. Annu Rev Neurosci 2003, 26:267-298.

45. Volles MJ, Lee SJ, Rochet JC, Shtilerman MD, Ding TT, Kessler JC, Lansbury PT: Vesicle permeabilization by protofibrillar alpha-synuclein: Implications for the pathogenesis and treatment of Parkinson's disease. Biochemistry 2001, 40(26):7812-7819.

46. Jenner $P$ : Oxidative mechanisms in nigral cell death in Parkinson's disease. MOVEMENT DISORD 1998, 13:24-34

47. Betarbet R, Sherer TB, Di Monte DA, Greenamyre JT: Mechanistic approaches to Parkinson's disease pathogenesis. Brain Pathol 2002 12(4):499-510.

48. Quilty MC, King AE, Gai WP, Pountney DL, West AK, Vickers JC, Dickson TC: Alpha-synuclein is upregulated in neurones in response to chronic oxidative stress and is associated with neuroprotection. EXP NEUROL 2006, 199(2):249-256.

49. Olanow CW: An Introduction to the Free-Radical Hypothesis in Parkinsons-Disease. Ann Neurol 1992, 32:S2-S9.

50. Mancuso C, Scapagnini G, Curro D, Stella AMG, De Marco C, Butterfield DA, Calabrese V: Mitochondrial dysfunction, free radical generation and cellular stress response in neurodegenerative disorders. Front Biosci 2007, 12:1107-1123

51. Bo J, Ming BY, Gang LZ, Lei C, Jia AL: Protection by puerarin against MPP+-induced neurotoxicity in PC12 cells mediated by inhibiting mitochondrial dysfunction and caspase-3-like activation. Neurosci Res 2005, 53(2):183-188

52. Zhou ZD, Yap BP, Gung AYT, Leong SM, Ang ST, Lim TM: Dopaminerelated and caspase-independent apoptosis in dopaminergic neurons induced by overexpression of human wild type or mutant alphasynuclein. Exp Cell Res 2005, 312(2):156-170

53. Desplats P, Lee HJ, Bae EJ, Patrick C, Rockenstein E, Crews L, Spencer B, Masliah E, Lee $S J$ : Inclusion formation and neuronal cell death through neuron-to-neuron transmission of alpha-synuclein. P Natl Acad Sci USA 2009, 106(31):13010-13015.

54. Volles MJ, Lansbury PT: Relationships between the sequence of alphasynuclein and its membrane affinity, fibrillization propensity, and yeast toxicity. J Mol Biol 2007, 366(5):1510-1522.

55. Wang MS, Zameer A, Emadi S, Sierks MR: Characterizing Antibody Specificity to Different Protein Morphologies by AFM. LANGMUIR 2009, 25(2):912-918

56. Yuan B, Sierks MR: Intracellular targeting and clearance of oligomeric alpha-synuclein alleviates toxicity in mammalian cells. Neurosci Lett 2009, 459(1):16-18.

57. Decker T, Lohmann-Matthes ML: A quick and simple method for the quantitation of lactate dehydrogenase release in measurements of 
cellular cytotoxicity and tumor necrosis factor (TNF) activity. J Immunol Methods 1988, 115(1):61-69.

58. Shahan TA, Siegel PD, Sorenson WG, Kuschner WG, Lewis DM: A Sensitive New Bioassay for Tumor-Necrosis-Factor. Journal of Immunological Methods 1994, 175(2):181-187.

59. Molina-Jimenez MF, Sanchez-Reus MI, Andres D, Cascales M, Benedi J: Neuroprotective effect of fraxetin and myricetin against rotenoneinduced apoptosis in neuroblastoma cells. Brain Res 2004, 1009(12):9-16.

doi: $10.1186 / 1471-2202-11-57$

Cite this article as: Wang et al., Curcumin reduces ?-synuclein induced cytotoxicity in Parkinson's disease cell model BMC Neuroscience 2010, 11:57

Submit your next manuscript to BioMed Central and take full advantage of:

- Convenient online submission

- Thorough peer review

- No space constraints or color figure charges

- Immediate publication on acceptance

- Inclusion in PubMed, CAS, Scopus and Google Scholar

- Research which is freely available for redistribution

Submit your manuscript at www.biomedcentral.com/submit
() BioMed Central 